\title{
Correction to: Nativity Homogeneity in Social Networks and Prostitution Patronage Among Male Migrant Laborers
}

\author{
Xiaozhao Yousef Yang ${ }^{1,2,3} \cdot$ Tingzhong Yang ${ }^{4}$
}

Published online: 5 May 2019

(c) The Author(s) 2019

\section{Correction to: AIDS and Behavior}

https://doi.org/10.1007/s10461-018-2357-1

The original version of this article unfortunately missed to add the affiliation of the corresponding author. The new affiliation is "Department of Sociology and Social Work, Sun Yat-sen University, Guangzhou, China".

The original article has been corrected.

The original article can be found online at https://doi.org/10.1007/ s10461-018-2357-1.

Xiaozhao Yousef Yang xyang7@murraystate.edu

1 Department of Sociology and Social Work, Sun Yat-sen University, Guangzhou, China

2 Department of Political Science and Sociology, Murray State University, Murray, KY, USA

3 Center for Tobacco Control Research, Zhejiang University, Hangzhou, China

4 Children's Hospital, Zhejiang University School of Medicine, Hangzhou, China 